\section{Japanese budget requests for international collaboration}

Tokyo

SupErConductors, AIDS (acquired immune deficiency syndrome), the Human Frontiers Science Program and in the budget requests for fiscal year 1988 submitted by Japanese government ministries and agencies last week. But tough negotiations lie ahead with the Ministry of Finance over the budget proposals.

The budget requests total $¥ 60.8$ million million ( $\$ 430,000$ million), 12 per cent up on this year. Sales of shares of Nippon Telephone and Telegraph, which will net the government several million million yen, will be used to cover part of the increase and to refund government bonds (about 20 per cent of the budget is swallowed by debt-servicing payments). Nevertheless, the Ministry of Finance plans to slash the requests to around $¥ 56$ million million by the end of this year when the budget will be submitted for Diet approval. sequencing of the human genome feature

At the end of August, the Council of Science and Technology, Japan's top science policy-making body which is Chaired by Prime Minister Yasuhiro Nakasone, recommended promotion of research into the immune, cerebral and nervous systems over the next ten years, attaching particular importance to AIDS research. The Health and Welfare Ministry has requested more than $¥ 2,000$ million (\$15 million) to combat AIDS in fiscal 1988. Although still small the budget request is more than an order of magnitude larger than this year. More than half ( $¥ 1,265$ million) is set aside for the development of anti-AIDS drugs and vaccines, including animal experiments. And $\$ 1.5$ million is requested for the World Health Organization's anti-AIDS programme.

The council also calls for basic research into the new superconducting oxides discovered by IBM Zurich last year.

The Science and Technology Agency

\section{Shuttle booster fired (at last)}

\section{Washington}

AFTER irksome delays caused first by a broken water hose and then (twice) by failure to reset all computers to a new countdown (Nature 329, 3; 1987), the redesigned booster for the space shuttle was successfully fired on 30 August at Morton Thiokol's Wasatch Facility in Utah. It ran at full thrust and for the full two-minute duration of the shuttle boost phase. Engineers will take several weeks to dismantle and inspect the booster and to analyse the data from $\mathbf{5 2 0}$ instruments measuring pressures, temperatures, strains and so on, but officials at both Morton Thiokol and NASA were evidently pleased by the belated but eventually trouble-free firing.

The purpose of this first full-scale test was to prove the basic soundness of the redesigned joints between the cylindrical sections of the booster body. A third $O$ to clasp the sections together. The failure of an O-ring in subfreezing temperatures caused the loss of Challenger last year, but the booster, long before the Challenger explosion. ring has been added, along with a metal lip after much searching Morton Thiokol engineers found no replacement material with better overall properties. Instead, electric heaters have been installed in the O-ring mountings.

During the redesign, engineers also took the opportunity to change the construction of the nozzle, especially its attachment to the body of the rocket. This had always been regarded as a potential weak spot in

Depending on the success or otherwise of three tests scheduled for November this year and February and March next year, as many as three firings of productionmodel boosters will be conducted between April and June 1988.

There has been some criticism that no test of a single isolated booster can truly simulate launch conditions, but short of an unmanned shuttle launch there is little else that can be done. Engineers at Morton Thiokol, their morale revived after last year's slump, say the tests will be "as good as they can be".

David Lindley

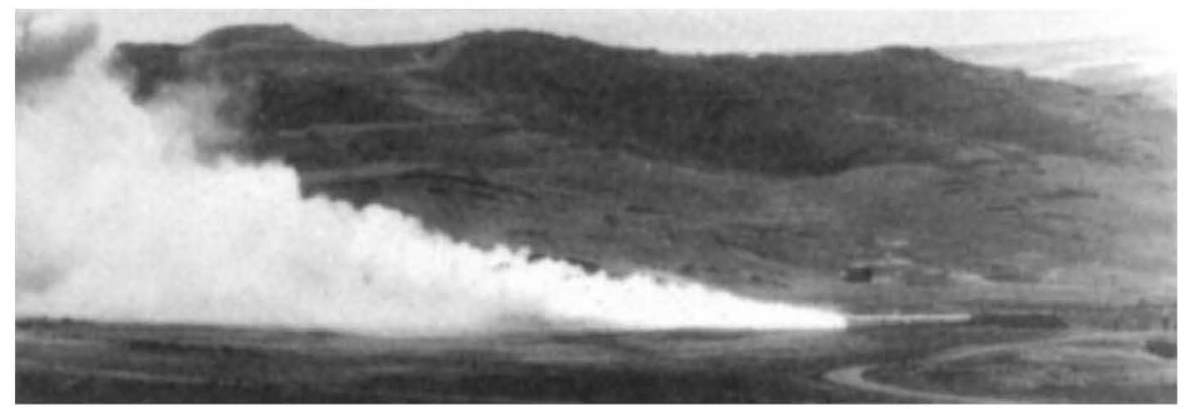

hopes to get $¥ 2,362$ million (\$17 million) in fiscal 1988 plus a similar amount ( $¥ 2,839$ million) in credit for the next two or three years to support superconductor research (the former budget is allotted to specific institutes, whereas the latter credit account is open to application from the agency’s institutes). Over $¥ 2,500$ million ( $¥ 1,035$ million in fiscal 1988 and $¥ 1,511$ million in three-year credit) is assigned to the National Research Institute for Metals to build high-field magnets $(80,40$ and 20 Tesla) which will be used to characterize the high-field properties of the new ceramics. The National Research Institute for Inorganic Materials also gets a large portion ( $¥ 280$ million in fiscal 1988 and $¥ 931$ million in two-year credit) for a new high-powered electron microscope to analyse the atomic and molecular structure of ceramic crystals.

MITI has requested comparable funding in the superconductor field. More than $¥ 1,500$ million (\$10 million) goes to basic theoretical work on the new hightemperature superconductors ( $¥ 770$ million) and their processing into thin films and devices ( $¥ 850$ million), largely under the ministry's category "basic technology for future industries" which includes research on biochips. An even larger sum ( $¥ 1,670$ million) is assigned to development of a $70,000-\mathrm{kW}$ superconducting generator, in MITI's energy-saving 'Moonlight Project'; conventional superconducting wire will be used in the armature of the generator. MITI plans to establish a privatel non-profit foundation, the "international superconductor industry and technology promotion centre", to support research on the new ceramics (see Nature 328, 282; 1987).

MITI's Eletrotechnical Laboratory has established links with the US National Bureau of Standards and the ministry's budget request includes $¥ 20$ million for joint research with the United States on superconductors. A programme to invite foreign researchers to Japan will also be created under the Science and Technology Agency's special promotion fund.

The prime minister asserted at the meeting of the Council of Science and Technology that the Human Frontiers Science Program, Japan's ambitious plan to promote international research into biological functions, will go ahead. But the funds requested for fiscal 1988 are small compared with the scale of project originally envisaged by MITI ( $¥ 1$ million million over 20 years).

MITI officials point out that, although the Frontiers budget is still small, several closely related programmes may eventually come under the wing of Frontiers. The Science and Technology Agency has requested $¥ 247$ million for research and development of techniques for sequencing long DNA sequences, such as the human genome.

David Swinbanks 